\title{
Detection of VIM- and IMP-type Metallo-Beta-Lactamase Genes in Acinetobacter baumannii Isolates from Patients in Two Hospitals in Tehran
}

\author{
Saba Davoodi 1, Mohammad Ali Boroumand 2,*, Saeed Sepehriseresht ${ }^{2}$, Leila Pourgholi ${ }^{2}$ \\ ${ }^{1}$ Department of Biology, Science and Research Branch, Islamic Azad University, Tehran, Iran \\ ${ }^{2}$ Department of Molecular Pathology, Tehran Heart Center, Tehran University of Medical Science, Tehran, Iran \\ ${ }^{*}$ Corresponding author: Mohammad Ali Boroumand, Department of Molecular Pathology, Tehran Heart Center, Tehran University of Medical Science, \\ Tehran, Iran. Tel: +98-2122367870; E-mail: maborumand@yahoo.com
}

Received: November 27, 2014; Revised: February 06, 2015; Accepted: March 12, 2015

Background: Acinetobacter baumannii, is an opportunistic pathogen and is responsible for numerous nosocomial infections. In recent years, this microorganism has been resistant to a wide range of antibiotics. One of the most important mechanisms of resistance in this microorganism is production of metallo-beta-lactamases (MBLs).

Objectives: The aim of this study was to detect VIM- and IMP-type metallo-beta-lactamase genes in Acinetobacter baumanniiisolates from patients in two Hospitals in Tehran.

Materials and Methods: 104 isolates were tested using the PCR method for the identification of VIM- and IMP-type genes.

Results: $\operatorname{vim} 1$, vim 2 , imp 1 and $\operatorname{imp} 2$ genes were detected in $6.7 \%, 41.7 \%, 50 \%$ and $1.7 \%$ of the isolates from Tehran Heart Center, and in $29.5 \%, 38.6 \%, 4.5 \%$ and $4.5 \%$ of the isolates from Shahid Mutahhari Hospital respectively.

Discussion: Our analysis revealed that the majority of the isolates had at least one of these genes, indicating that MBLs production is an important resistance mechanism in Acinetobacter baumannii.

Keywords: Acinetobacter baumannii; Imp1; Imp2; Metallo-beta-lactamase; Vim1;Vim2

\section{Background}

Acinetobacter baumanni is a non-fermentative Gram-negative coccobacilli belonging to the Moraxellaceae family. The genus Acinetobacter has different species, most of which are environmental and usually do not cause disease in humans. In recent years, however, strains of Acinetobacter baumannii have exhibited multi-drug resistance (MDR) and caused various infections such as those of the respiratory tract, blood, and skin amongst others. This microorganism is deemed a major problem in hospitals, not least in the intensive care unit (ICU), where control of various infections is difficult (1). Different mechanisms of antibiotic resistance are identified in Acinetobacter baumannii, including the widespread production of hydrolyzing enzymes known as metallobeta-lactamases (MBLs) such as IMP- and VIM-types, Class D carbapenemases. A new family of Class C cephalosporinases that has been recently detected in this genus, resist the porin loss, which changes the permeability of the bacterial outer membrane, and leads to the production of a broad spectrum of pumps named efflux pumps, which cause resistance to cefotaxime and a large number of other antibiotics (2).

The increased use of Beta-lactam antibiotics has prompted development in the production of Beta-lactamases in recent years (3). At least three major groups of MBLs have been identified: IMP, VIM and SPM types (4). The most effective mechanism of resistance relates to VIM and IMP MBLs. MBLs are the cause of Acinetobacter baumannii resistance to the newer generation of cephalosporins and carbapenems (2). Carbapenemases comprise a wide range of enzymes that are active against various antibiotics, including carbapenems such as imipenem, meropenem and ertapenem. IMP type carbapenemase was first detected in Gram-negative bacteria such as Pseudomonas aeruginosa and Acinetobacter species in Japan in the 1990s, and then spread slowly in Asia and then was also detected in Europe, Canada and Brazil. VIMtypes were first reported in Italy in 1999 and now have a geographical distribution in Europe, South America, 
Asia and The United Sates (3). Different results have been reported about the frequency of VIM- and IMPtype MBLs in different studies. Shahcheraghi et al. evaluated the existence of these genes in 100 Acinetobacter baumannii isolates from seven hospitals in Tehran and reported that none of them carried VIMor IMP-type MBL encoding genes (5). In this study, the VIM- and IMP-type MBL encoding genes were detected in Acinetobacter baumannii isolates from two hospitals of Tehran, IR Iran.

\section{Materials and Methods}

\subsection{Separation and Collection of Strains}

Totally, 104 clinical isolates of Acinetobacter baumannii were collected from patients in Tehran Heart Center (60 isolates) and Shahid Mutahhari Burns Hospital (44 isolates) in a 4-month period. Information regarding the specimens such as sex, age, site of specimen collection, etc. was recorded, and the isolates were identified via Gram staining and biochemical tests.

\subsection{Antibiotic Susceptibility Testing}

Imipenem susceptibility patterns were determined via disk diffusion method (Kirby-Bauer technique) using imipenem disks (MAST Co., England) on Muller-Hinton agar (Hi-Media, India). The results were interpreted according to the CLSI standard.

\subsection{DNA Extraction}

The DNA content of the isolates was extracted using boiling method. Briefly, the isolates were cultured on Muller-Hinton agar for $24 \mathrm{~h}$; a few colonies of each isolate were rinsed twice with sterile distilled water and boiled for $15 \mathrm{~min}$, followed by $4 \mathrm{~min}$ of treatment on ice before final centrifugation (5000 rpm) for $3 \mathrm{~min}$. The supernatant was preserved at $-70^{\circ} \mathrm{C}$ for further investigations.

\subsection{Polymerase Chain Reaction (PCR)}

In this study, four pairs of primers were used to detect vim 1, vim 2, imp 1 and imp2 genes (Table 1). The reaction mixture consisted of $2.5 \mu \mathrm{L} 10 \mathrm{X}$ buffer, 1.25 $\mu \mathrm{L} \mathrm{MgCl}_{2}(50 \mathrm{mM}), 0.25 \mu \mathrm{L}$ dNTPs $(10 \mathrm{mM}), 0.75 \mu \mathrm{L}$ of each primer $(10 \mu \mathrm{M}), 50 \mu \mathrm{g}$ template DNA, and $0.15 \mu \mathrm{L}$ of $\mathrm{Taq}$ DNA polymerase (2500 U. $\left.\mu \mathrm{L}^{-1}\right)$ (CinnaGen Co., Iran), in a final volume of $25 \mu \mathrm{L}$. PCR program for the amplification of vim 1 included the initial denaturation at $95^{\circ} \mathrm{C}$ for $4 \mathrm{~min}$ and 35 cycles of $95^{\circ} \mathrm{C}$ for $1 \mathrm{~min}$, primer annealing at $55^{\circ} \mathrm{C}$ for $30 \mathrm{sec}-$ onds and polymerization at $72^{\circ} \mathrm{C}$ for 45 seconds. The PCR program for amplification of vim2, imp 1 and imp 2 consisted of the initial denaturation at $95^{\circ} \mathrm{C}$ for 4 min and 35 cycles of $95^{\circ} \mathrm{C}$ denaturation for $1 \mathrm{~min}$, primer annealing at $53^{\circ} \mathrm{C}$ for $1 \mathrm{~min}$ and polymerization at $72^{\circ} \mathrm{C}$ for $1.5 \mathrm{~min}$. A final polymerization step was set at $72^{\circ} \mathrm{C}$ for $7 \mathrm{~min}$. A tube containing all components of the PCR reaction with human DNA was used as negative control. Strains of Pseudomonas aeruginosa VR-143/97 carrying vim 1, Pseudomonas putida NTU91/99 carrying vim 2 and two separate plasmids carrying imp1 and imp2 were used as positive controls.

\subsection{Detection and Electrophoresis of PCR Products}

Agarose gel (1\%) in borate buffer was used for electrophoresis. The voltage was set at $90-100 \mathrm{~V}$. The ethidium bromide staining $\left(0.5 \mu \mathrm{g} . \mathrm{mL}^{-1}\right)$ was used and the bands were observed using Gel-Doc instrument (Vilber Lourmat, France). A 50-1000 bp ladder (CinnaGen, Iran) was employed to determine the molecular weight of the DNA bands. All the data are presented as absolute frequencies and percentages. The data and result analyses were performed using statistical software SPSS version 13.

Table 1. Oligonucleotide primers and their related information

\begin{tabular}{|c|c|c|c|c|}
\hline $\begin{array}{l}\text { Primer } \\
\text { Name }\end{array}$ & Oligonucleotide sequence & $\begin{array}{l}\text { PCR product } \\
\text { size }(\mathrm{pb})\end{array}$ & $\begin{array}{c}\text { Annealing } \\
\text { temperature }\left({ }^{\circ} \mathrm{C}\right)\end{array}$ & Reference \\
\hline blaVIM1 & $\begin{array}{l}\text { Forward: 5'-TTA-TGG-AGC-AGC-AAC-GAT-GT-3' } \\
\text { Reverse: } 5 \text { '-CAA-AAG-TCC-CGC-TCC-AAC-GA-3' }\end{array}$ & 924 & 55 & Shibata et al. (2003) \\
\hline blaVIM2 & $\begin{array}{l}\text { Forward: 5'-ATG-TTC-AAA-CTT-TTG-AGT-AAG-3' } \\
\text { Reverse: } 5 \text { '-CTA-CTC-AAC-GAC-TGA- GGG-3' }\end{array}$ & 801 & 53 & Shibata et al. (2003) \\
\hline blalMP1 & $\begin{array}{l}\text { Forward: 5'-ACC-GCA-GCA-GAC-TCT-TTG-CC-3' } \\
\text { Reverse: 5'-ACA-ACC-AGT-TTT-GCC-TTA-CC-3' }\end{array}$ & 587 & 53 & Shibata et al. (2003) \\
\hline blalMP2 & $\begin{array}{c}\text { Forward: 5'-GTT-TTA-TGT-GTA-TGC-TTC-C-3' } \\
\text { Reverse: 5'AGC-CTG-TTC-CCA-TGT-A-C-3' }\end{array}$ & 678 & 53 & Shibata et al. (2003) \\
\hline
\end{tabular}




\section{Results}

Over a four-month period, 104 isolates of Acinetobacter baumannii were collected. Amongst a total of 60 isolates from Tehran Heart Center, 32 $(53.3 \%)$ and $28(46.7 \%)$ were isolated from male and female patients, respectively. At Shahid Mutahhari Burns Hospital, from a total of 44 isolates, 35 (79.5\%) and $9(20.5 \%)$ were isolated from male and female patients, respectively.

The specimens collected from patients at these two hospitals were from different sources (Figure 1).

$13(21.7 \%), 3(5 \%)$ and $44(73.3 \%)$ of the isolates from Tehran Heart Center and 10 (22.7\%), 8 (18.2\%) and $26(59.1 \%)$ of the isolates from Shahid Mutahhari Hospital had sensitive, intermediate and resistant pattern to imipenem, respectively.

PCR results demonstrated that $4(6.7 \%), 25$ $(41.7 \%), 30(50 \%)$ and $1(1.7 \%)$ of the isolates from Tehran Heart Center and 13 (29.57\%), 17 (38.6\%), 2 $(4.5 \%)$ and $2(4.5 \%)$ of the isolates from Shahid Mutahhari Hospital carried vim1, vim2, imp1 and imp2 genes respectively (Figure 2).

From the 60 isolates at Tehran Heart Center, 2 (3.3\%) carried both vim 1 and vim 2 genes, $13(21.7 \%)$ isolates carried both imp1 and vim2 genes, and 15 $(25 \%)$ isolates carried none of them. Of the 44 isolates examined at Mutahhari Hospital, $4(9.1 \%)$ isolates carried both vim 1 and vim 2 genes, 2 (4.5\%) isolates carried both imp 1 and vim2 genes, 1 (3.3\%) isolate carried both imp2 and vim1 genes and $17(38.6 \%)$ isolates carried none of them. $75 \%$ of the isolates at Tehran Heart Center and $61 \%$ of the isolates at Shahid Mutahhari Burns Hospital carried at least one of these four genes.

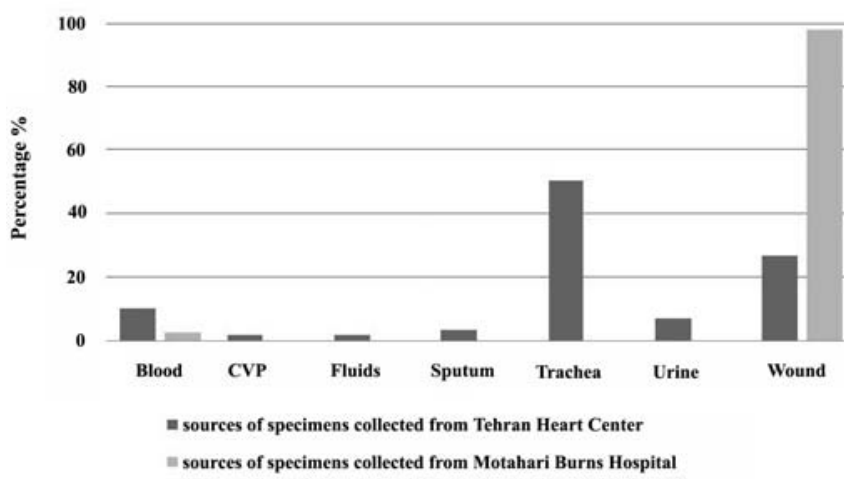

Figure 1. Different specimen sources for Acinetobacter baumannii isolates of Tehran Heart Center and Shahid Mutahhari Burns Hospital patients. The majority of the specimens from Shahid Mutahhari Burns Hospital patients were collected from wound, whereas trachea was the most frequent source of $A$. baumannii isolated from Tehran Heart Center patients
A
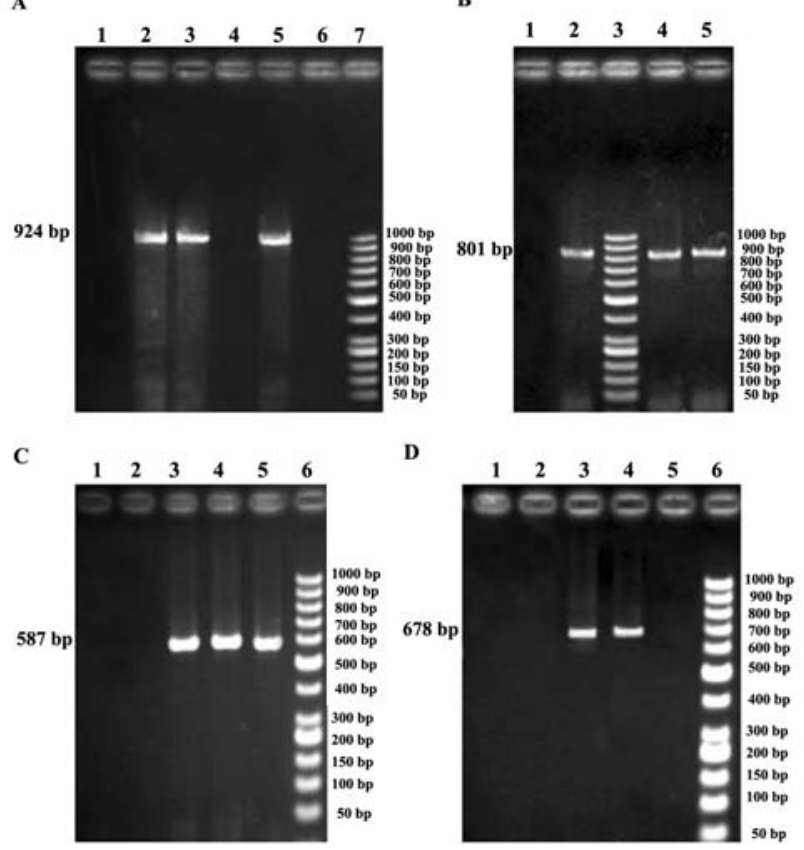

Figure 2. A: Gel electrophoresis of vim1 PCR products. Lines 1, 2 and 7 show the negative control, positive control and marker respectively; lines 3 and 5 show the positive isolates; and lines 4 and 6 show the negative isolates. B: Gel electrophoresis of vim2 PCR products. Lines 1, 2 and 3 are related to the negative control, positive control and marker, respectively; and lines 4 and 5 are related to the positive isolates. C: Gel electrophoresis of imp1 PCR products. Lines 2, 3 and 6 show the negative control, positive control, and marker respectively; and lines 1, 4, and 5 show the positive isolates. D: Gel electrophoresis of imp2 PCR products. Lines 2, 3, and 6 are related to the negative control, positive control and marker respectively; line 4 is related to the positive isolate; and lines 1 and 5 are related to the negative isolates

\section{Discussion}

Acinetobacter baumannii is the sixth most common Gram-negative bacterium isolated from ICU patients. The bacterium's high rate of mortality, increase in the MDR phenotype, easy spread and potential for opportunism constitute a serious threat to the clinical centers. The clinical importance of Acinetobacter baumannii has increased, especially in recent years, due to its remarkable ability to acquire resistance. Indeed, it is due to this ability that Acinetobacter has become a problematic organism in recent years. The most important mechanism of resistance to beta-lactam antibiotics in this bacterium is the production of beta-lactamases (2). Imipenem is an effective antibiotic against Acinetobacter baumannii and is resistant to most betalactamases; be that as it may, it is inhibited by a group of these enzymes, metallo-beta-lactamases, which fortunately has been found only in a few strains of bacte- 
ria such as Pseudomonas aeruginosa and Acinetobacter baumannii. Acinetobacter resistance to imipenem is growing and one of the ways to acquire resistance to imipenem in this organism is the acquisition of MBL-encoding genes (Gordon and Wareham, 2010) such as vim1, vim2, imp1 and imp2.

In this study, Acinetobacter baumannii resistance frequencies to imipenem at Tehran Heart Center and Shahid Mutahhari Burns Hospital were 73.3\% and $59.1 \%$, respectively. Halstead et al. Studied 851 Acinetobacter isolates and showed that $39.8 \%$ of them, collected from 76 centers in the United States between 2004 and 2005, were resistant to imipenem (Halstead et al., 2007). In a study on 75 Acinetobacter isolated from civilian and military patients from Iraq and Afghanistan in 2006, Hujer et al. showed that 20\% of the isolates were resistant to imipenem (Hujer et al., 2006). In contrast, in a study on the American servicemen injured in Iraq in 2007, Scott et al. reported that only $10 \%$ of the Acinetobacter baumannii strains were resistant to carbapenems (Scott et al., 2007). Hawly et $a l$, in their study on the American servicemen wounded in 2007, showed that amongst 142 strains of Acinetobacter baumannii, 37\% were resistant to imipenem (Hawley et al., 2007). In Latin America in a broad study between 2002 and 2004, Unal et al. demonstrated that $29 \%$ of the Acinetobacter isolates were resistant to meropenem or imipenem (Unal and Garcia-Rodriguez, 2005). In this study at Tehran Heart Center and Shahid Mutahhari Burns Hospital, imipenem resistance to Acinetobacter baumannii was higher than that reported by previous studies. The differences are probably due to the difference between geographical regions, medical centers and different regimens of antibiotic therapy.

The frequencies of vim1, vim2, impl and imp2 genes were $6.7 \%, 41.7 \%, 50 \%$ and $1.7 \%$ at Tehran Heart Center and 29.57\%, 38.6\%, 4.5\% and 4.5\% at Shahid Mutahhari Burns Hospital, respectively. In a study conducted between 2000 and 2001 in 28 hospitals in Korea, Lee et al. studied 38 MBL-producing isolates of Acinetobacter, of which 27 (10.1\%) and 11 (4.1\%) carried vim 2 and imp1, respectively (Lee et al., 2003). In 2003 in Korea, Oh et al. examined 31 isolates of Acinetobacter baumannii in terms of the presence of vim1, vim 2 and impl genes and amongst them only $4(12.9 \%)$ isolates carried vim 2 while the others lacked each of the four genes (Oh et al., 2003). In 2004, Sader et al. studied 33 isolates of Acinetobacter in Latin America, amongst which 7 isolates (21\%) had impl gene (Sader et al., 2004). In 2007 in Spain, Ruiz et al. examined 83 isolates of Acinetobacter bauman- nii with respect to the presence of vim and imp genes and demonstrated that all of them lacked these two genes (Ruiz et al., 2007). In 2007 in Greece, Iknomidies et al. studied 87 isolates of Acinetobacter baumannii for the presence of vim 1 gene and found that only $2(2.3 \%)$ isolates carried vim 1 (Iknomidies et al., 2007). In 2010, in India, Azim et al. examined 38 isolates of Acinetobacter baumannii and found that 20 (52.6\%) and 14 (36.8\%) isolates carried imp and vim genes, respectively (Azim et al., 2010). In Iran, Shahcheraghi et al. detected no VIM- or IMP-type MBL-encoding genes in 100 Acinetobacter baumannii isolates from seven hospitals of Tehran (Shahcheraghi et al., 2011).

As can be seen, there has been a considerable differences between the frequencies of VIM- and IMPtype MBL-encoding genes in various regions of the world in different years. These differences could also result from differences in geographical regions, antibiotic therapy regimens, and the number of isolates examined. To resolve this controversy and to achieve reliable statistics on the frequency of MBL-encoding genes, a comprehensive study comprising a collection of specimens obtained from several countries at a given time interval with complete data on specimens and patients such as the site of specimen collection, ward of hospitalization and antibiotic treatment regimen through a well-defined and constant technique is recommended.

Overall $75 \%$ of the isolates in Tehran Heart Center and $61.4 \%$ of the isolates in Shahid Mutahhari Burns Hospital had at least one of the above-mentioned four genes. This indicates that the production of MBLs is one of the most important mechanisms of resistance to imipenem by Acinetobacter baumannii in these two hospitals. In addition, in this study $25 \%$ of the isolates in Tehran Heart Center and $38.6 \%$ of the isolates in Shahid Mutahhari Burns Hospital lacked these four genes. The resistance to imipenem in these isolates may have been the consequence of other mechanisms of resistance in this organism. Resistance among the isolates that lacked these four genes may have been due to other MBL enzymes, whose genes were not examined in this study.

Given the high frequency of MBL-coding genes, high levels of resistance to imipenem amongst the Acinetobacter baumannii isolates from hospitalized patients in Tehran Heart Center and Shahid Mutahhari Burns Hospital, the possibility of resistance transfer amongst different bacteria and amongst different strains of a bacterium, and the likelihood of the indiscriminate use of antibiotics inducing resistance in bac- 
teria, it is vitally important that arrangements be made to reduce usage of key antibiotics such as imipenem in hospitals, perform accurate health protocols to prevent the spread of imipenem-resistant bacteria in the hospitals through personnel or hospital equipment, and finally carry out regular and periodic examination of imipenem resistance and frequency of its encoding genes.

\section{Acknowledgments}

The authors would like to thank the personnel of Molecular Pathology and Clinical Laboratory department of Tehran Heart Center.

\section{References}

1. Gordon NC, Wareham DW. Multidrug-resistant Acinetobacter baumannii: mechanisms of virulence and resistance. Int $J$ Antimicrob Agents. 2010;35:219-226. DOI: http://dx.doi.org/ 10.1016/j.ijantimicag.2009.10.024

2. Thomson JM, Bonomo RA. The threat of antibiotic resistance in Gram-negative pathogenic bacteria: $\beta$-lactams in peril! Curr Opin Microbiol. 2005;8:518-524. DOI: 10.1016/j.mib. 2005.08.014

3. Jacoby GA, Munoz-Price LS. Mechanisms of disease the new $\beta$-lactamases. New Engl J Med. 2005;352:380-391. DOI: 10. 1056/NEJMra041359

4. Shibata N, Doi Y, Yamane K, Yagi T, Kurokawa H, Shibayama K, Kato H, Kai K, Arakawa Y. PCR Typing of Genetic Determinants for Metallo- $\beta$-Lactamases and Integrases Carried by Gram-Negative Bacteria Isolated in Japan, with Focus on the Class 3 Integron. J Clin Microbiol. 2003;41:5407-5413. DOI: 10.1128/JCM.41.12.5407-5413. 2003

5. Shahcherghi F, Abbasalipour M, Feizabadi MM, Ebrahimipour GH, Akbari N. Isolation and genetic characterization of metallo-â-lactamase and carbapenamase producing strains of Acinetobacter baumannii from patients at Tehran hospitals. Iran J Microbiol. 2011; 3:68-74.

6. Halstead DC, Abid J, Dowzicky MJ. Antimicrobial susceptibility among Acinetobacter calcoaceticus-baumannii complex and Enterobacteriaceae collected as part of the Tigecycline Evaluation and Surveillance Trial. J Infect. 2007;55:49-57. DOI: http://dx.doi.org/10.1016/j.jinf.2006.11.018

7. Hujer KM, Hujer AM, Hulten EA, Bajaksouzian S, Adams JM, Donskey CJ, Ecker DJ, Massire C, Eshoo MW, Sampath R, Thomson JM, Rather PN, Craft DW, Fishbain JT, Ewell AJ, Jacobs MR, Paterson DL, Bonomo RA. Analysis of antibiotic resistance genes in multidrug-resistant Acinetobacter sp. isolates from military and civilian patients treated at the Walter Reed Army Medical Center. Antimicrob Agents Chemother. 2006;50:4114-4123. DOI: 10.1128/AAC. 00778-06

8. Scott P, Deye G, Srinivasan A, Murray C, Moran K, Hulten E, Fishbain J, Craf DT, Riddell S, Lindler L, Mancuso J, Milstrey E, Bautista CT, Patel J, Ewell A, Hamilton T, Gaddy C, Tenney M, Christopher G, Petersen K, Endy T, Petruccelli
B. An outbreak of multidrug-resistant Acinetobacter baumannii-calcoaceticus complex infection in the US military health care system associated with military operations in Iraq. Clin Infect Dis. 2007;44:1577-1584. DOI: 10.1086/518170

9. Hawley JS, Murray CK, Griffith ME, McElmeel ML, Fulcher LC, Hospenthal DR, Jorgensen JH. Susceptibility of Acinetobacter strains isolated from deployed U.S. military personnel. Antimicrob Agents Chemother. 2007; 51:376-378. DOI: 10.1128/AAC.00858-06

10. Unal S, Garcia-Rodriguez JA. Activity of meropenem and comparators against Pseudomonas aeruginosa and Acinetobacter spp. isolated in the MYSTIC Program, 20022004. Diagn Microbiol Infect Dis. 2005;53:265-271. DOI: http://dx.doi.org/10.1016/j.diagmicrobio.2005.10.002

11. Lee K, Lee WG, Uh Y, Ha JY, Cho J, Chong Y, the Korean Nationwide Surveillance of Antimicrobial Resistance Group. VIM- and IMP-Type Metallo- $\beta$-lactamase- Producing Pseudomonas spp. and Acinetobacter spp. in Korean Hospitals. Emerg Infect Dis. 2003;9(7):868-871. DOI: 10.3201/eid0907.030012

12. Oh EJ, Leea S, Parka YJ, Parka JJ, Parka K, Kimb SI, Kangb MW, Kim BK. Prevalence of metallo-beta-lactamase among Pseudomonas aeruginosa and Acinetobacter baumannii in a Korean University hospital and comparison of screening methods for detecting metallo-h-lactama. J Microbio Meth. 2003;54:411-418.

13. Sader HS, Castanheira M, Mendes RE, Toleman M, Walsh TR, Jones RN. Dissemination and diversity of metallo-â-lactamases in Latin America: report from the SENTRY Antimicrobial Surveillance Program. Int J Antimicrob Ag. 2005;25:57-61. DOI: http://dx.doi.org/10.1016/j.ijantimicag.2004.08.013

14. Ruiz M, Marti S, Fernandez-Cuenca F, Pascual A, Vila J. High prevalence of carbapenem-hydrolysing oxacillinases in epidemiologically related and unrelated Acinetobacter baumannii clinical isolates in Spain. Clin Microbiol Infect. 2007; 13:1192-1198. DOI: http://dx.doi.org/10.1111/j.1469-0691. 2007.01825.x

15. Ikonomidis A, Ntokou E, Maniatis AN, Tsakris A, Pournaras S. Hidden VIM-1 Metallo-beta-Lactamase Phenotypes among Acinetobacter baumannii Clinical Isolates. J Clin Microbiol. 2007;46(1):346-349. DOI: 10.1128/JCM.01670-07

16. Azim A, Dwivedi M, Rao PB, Baronia AK, Singh RK, Prasad KN, Poddar B, Mishra A, Gurjar M, Dhole TN. Epidemiology of bacterial colonization at intensive care unit admission with emphasis on extendedspectrum beta-lactamase- and metallobeta-lactamase producing Gram-negative bacteria - an Indian Experience. J Med Microbiol. 2010;59:955-960. DOI: 10. 1099/jmm.0.018085-0

17. Marais E, de Jong G, Ferraz V, Maloba B, Duse AG. Interhospital transfer of pan-resistant Acinetobacter strains in Johannesburg. South Africa Am J Infect Control. 2004; 32:278-281. DOI: http://dx.doi.org/10.1016/j.ajic.2003.11. 004 